This document is the accepted manuscript version of the following article:

Maag, S., \& Fischer, M. (2018). Why government, interest groups, and research coordinate: the different purposes of forums. Society and Natural Resources, 31(11), 1248-1265. https://doi.org/10.1080/08941920.2018.1484973

\title{
Why Government, Interest Groups, and Research Coordinate: The Different Purposes
}

\section{of Forums}

Simon Maag and Manuel Fischer*

\section{*Corresponding author}

Forums are organizations that facilitate coordination among actors from different societal sectors such as government, interest groups, and research. Forums can serve various purposes that we represent on two dimensions. The first dimension, sector orientation, assesses the degree to which a forum serves the needs of a specific societal sector. The second dimension, advocacy orientation, refers to the extent to which a forum is oriented toward advocating the shared interests of its members. The empirical application to a set of 36 forums in Swiss habitat and land use policy shows that both orientations capture important differences between forums. An improved understanding of these differences contributes to answering some key questions of forum research, such as those related to forum outputs, the role of forums in governance systems, or actors' incentives of forum participation.

Simon Maag, Environmental Social Sciences, Eawag

Überlandstrasse 133, CH-8600 Dübendorf

+4158765 6451, simon.maag@eawag.ch

Manuel Fischer, Environmental Social Sciences, Eawag, and Institute for Political Science, University of Bern

Überlandstrasse 133, CH-8600 Dübendorf +41 58765 5676, manuel.fischer@eawag.ch

Keywords: Forums; typology; sector orientation; advocacy orientation; environmental governance; Switzerland 


\section{Introduction}

The governance of complex issues requires coordination among actors from different societal sectors such as government, interest groups, and research (Ansell and Gash 2008; Emerson et al. 2012; Bryson et al. 2006). However, these actors have different goals and priorities, organizational structures, and professional languages (Huxham et al. 2000), making coordination between them a major challenge. To overcome this challenge, forums have evolved that specialize in coordination among the various actors. In this article, the term "forum" serves as an umbrella concept for all kinds of organizations that foster cross-sectoral coordination. Besides forums (Kinzig and Starrett 2003; Bates et al. 2013; Berardo et al. 2015; Leach et al. 2014), many other labels are used in the relevant literature such as “boundary organizations" (Guston 2001; Crona and Parker 2011; Carr and Wilkinson 2005), "bridging organizations" (Kowalski and Jenkins 2015; Crona and Parker 2012) or various combinations of "platform", "partnership", or "collaboration" with attributes such as "crosssectoral", "multisector", "multi-stakeholder", or "collaborative" (Selsky and Parker 2005; Koontz and Johnson 2004; Leach et al. 2002; Bauer and Steurer 2014; Hahn and Pinkse 2014; Agranoff 2006; Lubell 2004; Lubell et al. 2010; Siddiki and Goel 2017; Imperial 2005; Emerson and Nabatchi 2015; Ansell and Gash 2008; Huxham et al. 2000; Emerson et al. 2012).

This multitude of labels reflects important differences between forums, but also causes similarities to go unnoticed because of an artificial fragmentation of the literature. In order not to neglect these similarities, this article uses a broad and inclusive concept that defines forums as organizations fostering cross-sectoral coordination. In fact, the creation of crosssectoral coordination is the common denominator of almost all existing definitions in the

literature and the corresponding labels. ${ }^{1}$ By relying on a broad definition, the article responds to the repeated call for an umbrella concept (Imperial 2005; Mandell and Steelman 2003). 
However, a broad definition automatically leads to heterogeneity among the organizations considered as forums. In particular, the forums included under such a broad definition differ with regard to the purposes for which they are designed and for which their members gather. The present paper addresses this heterogeneity in purposes by introducing a two-dimensional concept of forum purpose. . The first dimension, sector orientation, refers to the degree to which a forum's purpose is oriented towards the specific needs of a particular societal sector (government, interest groups, or research). The second dimension, advocacy orientation, captures the extent to which a forum's purpose is oriented towards advocating the shared interests of its members towards policy makers and the public. The two dimensions highlight the fact that the purpose of forums is often not limited to simple cross-sectoral coordination such as information sharing or search for common ground. Instead, in many cases, forum purposes are geared to the specific needs of a societal sector (sector orientation), and to the advocacy for shared interests and beliefs of its members (advocacy orientation). The two dimensions can be used as a typology where the combinations of the respective extremes of both dimensions represent theoretical ideal types.

By introducing the two dimensions of forum purpose, this article makes at least four contributions to the various bodies of literature that deal with forums. First, by starting from an inclusive definition of forums and then differentiating internally, it allows for a comprehensive perspective on the full spectrum of forums. It thereby connects various strands of literature that can enrich each other. Second, this article fleshes out a set of variables that is relevant for answering three of the most frequently discussed research questions about forums: The question about the factors that influence forums' capacity to deliver outputs, the question about the roles that forums play in the in overall governance of complex issues, and the question about the incentives for actors to participate in forums. Third, for future empirical studies on forums, the conceptual clarity introduced by the two 
dimensions and the corresponding ideal types provide a basis for a well-reasoned and transparent case selection, including the discussion of borderline cases. Finally, from a more practical perspective, the typology can help forum managers to compare their own forums to similar organizations and learn from them by facilitating the identification of best practices (Margerum 2008; Selsky and Parker 2010).

The remainder of this article consists of three parts. The first, conceptual part establishes the two dimensions of forum purpose. This includes a discussion of how the dimensions and the corresponding ideal types integrate existing forum definitions, and how they relate to existing classifications. The second, empirical part puts the theoretical concept to concrete terms by demonstrating how it manifests in a sample of 36 forums in Swiss habitat and land use governance, thereby pointing out a number of methodological challenges. With this empirical material in mind, the third part returns to the conceptual level. It discusses how the two dimensions of forum purpose can help answering three of the most prominent questions in existing research of forums.

\section{The Multi-Layered Nature of Forum Purposes}

This article uses "forum" as an umbrella concept for organizations that aim at coordination among actors from different societal sectors (government, interest groups, and research) in a given issue area. Accordingly, an outstanding feature of forums is their cross-sectoral membership composition. The fact that they have members from different sectors implies that they do not simply aggregate the interests of one particular sector, thus differentiating them from interest group federations such as trade associations or civil society umbrella organizations. Furthermore, forums have formal institutional structures, creating repeated, organized interaction among a clearly defined set of members, independently of a policy process. This relatively high degree of institutionalization differentiates forums from informal 
advocacy coalitions (Jenkins-Smith et al. 2014) or simple actor networks (Fischer and Leifeld 2015). However, there are of course borderline cases of forums that resemble interest group federations, advocacy coalitions or networks in certain respects. We discuss these issues in the theoretical and empirical parts.

According to established theoretical frameworks, forums are responses by political leaders or entrepreneurs to challenges posed by the "system context" (Emerson et al. 2012), "initial conditions" (Bryson et al. 2006), or "starting conditions" (Ansell and Gash 2008) - that is, the political, legal, socioeconomic, and environmental contexts that create a demand for cross-sectoral coordination. The immediate driver that encourages the formation of forums is typically "sector failure" (Bryson et al. 2006) or "sector interdependence" (Emerson et al. 2012), that is, the pressure to cooperate if problems cannot be solved within the existing networks of a single sector.

However, forums do not come into existence without leadership (Hahn et al. 2006; Emerson and Nabatchi 2015). There is always an initiator or a group of initiators and these initiators are often not exclusively motivated by the general public interest, but at the same time pursue some type of self-interest. This element of self-interest tends to get little attention in the literature on forums. In fact, notions are widespread that forums are designed to "[...] carry out a public purpose that could not otherwise be accomplished" (Emerson et al. 2012), "create public value" (Imperial 2005) or "[...] elaborate recommendations concerning the management strategies that are most suitable for all [...]" (Vasseur et al. 1997). While not entirely rejecting these claims, we argue that forum purposes are often multi-layered. At the top layer, forums indeed often define the promotion of relatively broad, generally accepted issues as their purpose, such as for example environmental protection, sustainable development or health promotion. However, at another layer, many forums serve the specific needs of actors from one of the societal sectors involved (Fischer and Leifeld 2015). 
Accordingly, Bates et al. (2013) observed that "[forums] may be specific to a particular type of organization or industry." For example, within a forum, leaders from the government sector may strive to gain resources from other sectors (such as the market power of firms and industry associations, the knowledge of researchers, or the mobilization capacity of nongovernmental organizations) to successfully accomplish their task of policy making and implementation. Leaders from industry, in turn, might need cooperation with government actors or not-for-profit organizations for improving conditions to conduct their business. Researchers, finally, might rely on forums to increase the practical relevance of their work.

\section{Two Dimensions of Forum Purpose}

\section{Sector Orientation}

This insight regarding the multi-layered nature of forum purpose underlies the first dimension our two-dimensional concept of forum purpose: sector orientation. Sector orientation refers to the degree to which a forum's purpose is oriented towards the specific needs of one of the societal sectors involved. Along with the distinction among three societal sectors, there are three possible sector orientations: government orientation, interest group orientation, or research orientation (for similar distinctions between three sectors, see Edelenbos et al. 2011; Crona and Parker 2012; Krick 2015). These three sectors have different and sometimes opposing goals, different organizational structures and professional languages, different sets of knowledge, and fulfill different functions in the political system (Huxham et al. 2000; Edelenbos et al. 2011).

First, the government sector (including public administration) has the task to develop, set, and implement binding rules (Crona and Parker 2012). Actors from the government sector tend to strive for compromises among different societal actors and feasible solutions (Ingold and Varone 2012). The purpose of government-oriented forums therefore is oriented towards 
mobilizing actors from different sectors in support of policy making and implementation (see, e.g., Ansell and Gash 2008). Second, the role of the interest group sector is to organize and represent different types of private and public interests in society, and to feed these interests into the policy making process (Crona and Parker 2012). We conceive of the interest group sector in a broad way, including trade associations, professional associations, civil society groups, as well as individual firms and private persons representing their interests (Berry and Wilcox 2015). While these actors defend very different substantive interests, they all have a similar role within the governance system, as compared to government and research: They organize and represent their specific interests, or the interests of their constituents (Dür and Bièvre 2007). The purpose of interest group-oriented forums is thus to support interest groups in their pursuit of interest representation. ${ }^{2}$ Third, the priority of actors from the research sector (universities and other research centers, science societies) is to produce complex and generalizable knowledge. Even though they tend to prioritize methodological rigor over applicability of their knowledge in policy and practice (Crona and Parker 2012), many of them are interested in the dissemination of their knowledge beyond the academic context and in influencing policy making (Keller 2009). Hence, research-oriented forums are typically oriented towards the collaborative production and dissemination of scientific knowledge, influencing the policy agenda or fostering science-based governance.

The three sector orientations can be considered continuous variables, indicating degrees of sector orientation. Alternatively, they can serve as variables underlying a typology of forums where forums with extreme sector orientations represent ideal types: government-oriented forums, interest group-oriented forums, and research-oriented forums. A fourth ideal type is the "balanced" type that has no predominant sector orientation, and is thus more or less equally oriented towards all sectors. 
The basic idea of sector-orientation can be found in many existing forum typologies (Koontz and Johnson 2004; Koontz et al. 2004; Moore and Koontz 2003; Diaz-Kope and MillerStevens 2015; Bidwell and Ryan 2006; Andrews and Entwistle 2010; Bryson et al. 2006; Hardy 2010). For example, the typology by Moore and Koontz (2003) is also based on the assumption that not all forums are balanced in terms of the societal sectors they represent. They distinguish between citizen-based (primarily composed of private citizens), agencybased (primarily composed of public representatives), and mixed partnerships (equal mix of public and private representatives). A similar idea also underlies the typology suggested by Selsky and Parker (2010). They distinguish between "social-issue platforms" (focusing on a social problem) and "societal-sector platforms" (focusing on sector-specific problems that cannot be solved by one sector alone). While the former closely corresponds to our balanced type, the latter is a summary category for the other three sector orientations in the present article. In line with our categorization of sectors, Edelenbos et al. (2011) or Giebels et al. (2015), in studies on knowledge (co-)production in water and ecosystem management, also distinguish between bureaucratic, scientific, and stakeholder knowledge.

\section{Advocacy Orientation}

The second dimension of forum purpose, advocacy orientation, refers to the extent to which a forum is oriented towards advocating the shared interests or beliefs of its members towards decision-makers or the public. As with sector orientation, one can think of the advocacy dimension as a continuum with ideal types at its endpoints, the ideal types being "advocacy forums" (very strong advocacy orientation) and "background forums" (very weak or complete absence of any advocacy orientation). For forums with a strong advocacy orientation, sensitizing, influencing and convincing policy makers or the public is their main purpose. Ideal type advocacy forums are similar to what is known as "advocacy coalitions" in 
the literature on policy making processes (Jenkins-Smith et al. 2014; Sabatier 1988), however, advocacy coalitions are usually less institutionalized than forums, and advocacy is their sole purpose while forums serve wider coordination purposes.

By contrast, for forums with weak advocacy orientation, influencing decision-makers or the public is a side effect at best. They mostly stay away from the politicized venues where opposing societal interests and beliefs are openly promoted and negotiated. Instead, background forums either focus on low-conflict technical aspects where decision-makers and the public are barely involved (and thus do background work), or they address potentially high-conflict issues, but do not aim to publicly defend a joint position (and thus explicitly decide to stay in the background and not engage in advocacy). Forums with weak advocacy orientation typically concentrate on outputs such as information exchange, networking, or the establishment of trust among actors (Fischer and Leifeld 2015; Lubell et al. 2010; Berardo 2009; Feldman and Khademian 2007; Bryson et al. 2006).

The idea behind the advocacy dimension appears repeatedly in the forum literature, though it is usually not a core issue. One exception is Glasbergen's (2011) “Ladder of Partnership Activity". It points to the fact that forums vary with respect to the scope and intensity of the activities they pursue. At the bottom of the ladder, forums focus exclusively on 'internal interactions' (interactions among the partners themselves to create trust, consensus, and common knowledge) while at the top, forums engage in 'external interactions' (interactions aimed at changing markets or political orders). Also Agranoff's (2006) distinction between informational, developmental, outreach, and action networks can be seen as a conceptualization of the same basic idea. Furthermore, in many publications, advocacy appears as one of several forum outputs. For example, Koontz and colleagues consider 'public awareness', 'lobbying and petitioning', and 'government pressure' typical forum outputs (Koontz and Johnson 2004; Koontz and Thomas 2006; Moore and Koontz 2003), 
Gustafson and Hertting (2017) include 'influence political decisions', and Imperial (2005) lists 'educating decision makers and public' as forum outputs. According to these authors, forums might play the role of interest groups. However, other publications do not even mention advocacy as a possible forum purpose or remain vague (Lubell 2004; Lubell et al. 2002; Bryson et al. 2006; Ansell and Gash 2008). The relative absence of forums' advocacy orientation in the respective discussion reflects the focus of this literature on forums that concentrate on solving collective action problems or on government advice, and thus tend to operate in the background.

Strong advocacy orientation is not limited to forums with an interest group-orientation. It also exists among research-oriented forumsas the empirical part of this paper will demonstrate. In fact, research-oriented forums frequently aim to promote awareness of topics that, in the eyes of the forum members, do not receive sufficient attention from decision-makers and the public (e.g., biodiversity). On the other side, there are also interest group-oriented forums where advocacy is insignificant. This holds particularly true for forums whose purpose is to provide an industry sector (e.g., agriculture) or an alliance of public interest groups (e.g., development aid) with knowledge and networks at an operational level.

\section{Combining both dimensions}

Figure 1 shows a graphical representation of the sector and advocacy orientations of forums. The three sector orientations are plotted horizontally with three vectors for each of the three orientations. In the middle is the balanced ideal type that has no predominant sector orientation. The outer dashed circle represent the fuzzy border between organizations that can be considered forums and other types of organizations. The ideal types would lie just inside the dashed line on the respective vectors (with the balanced type in the middle). Outside the dashed line are organizations with no cross-sectoral coordination character such as 
government agencies, interest groups, or research institutions. A borderline case would be, for example, a commission where experts from different sectors are employed by the government to fulfill an exclusively administrative purpose such as policy evaluation or reviewing of applications for subsidy payments. In this case, it is questionable whether crosssectoral coordination is still central enough to consider the organization a forum. In fact, the experts are part-time government employees and do not gather for the explicit purpose of coordination among the sectors to which they belong. Advocacy orientation appears on the vertical dimension in Figure 1. Ideal type background forums are at the bottom of the cylinder while ideal type advocacy forums are located at the top. Between them are forums with intermediate levels of advocacy orientation.

Forums can, of course, lie anywhere in this forum space. As an example, a permanent government advisory board is strongly oriented towards the knowledge needs of policy makers (strong government-orientation), but to some extent is also designed for interest groups to feed their interests and beliefs into the political process (intermediate interest group-orientation). Research orientation is weak or absent. Such a forum would therefore be located to the left of the government vector (somewhat towards the interest-group vector) near the dashed borderline. If the government advisory board should also allow researchers to disseminate their knowledge, it would be located closer to the center, towards the balanced ideal type. Often, advisory boards operate in the background and do not advocate publically for a particular position. Therefore, such a forum would be at the bottom of the cylinder.

[Figure 1 here] 
It should be noted that both dimensions of forum purpose are dynamic, and forums can move along these dimensions over time (Emerson and Nabatchi 2015; Huxham et al. 2000). It is quite likely that the purpose of a forum changes over time as membership composition changes, intermediate goals are accomplished, or the system context evolves.

\section{Forums in Swiss Habitat and Land Use Policy Making}

In this section, a set of 36 forums active at the national level in Swiss habitat and land use governance (habitats for wildlife and plants, biodiversity, landscapes, natural disaster prevention/protection) is analyzed and classified along both dimensions of forum purpose. The aim of this empirical application is twofold: first, it demonstrates that the twodimensional concept of forum purpose is meaningful not only theoretically but also empirically. Second, it points out methodological challenges related to the empirical assessment of forum purpose.

When identifying the 36 forums, we relied on an operational definition of forums in line with our theoretical definition. Any organization can potentially be considered a forum if at least one representative of at least two of the following sectors are members of the organization: public administration, interest groups (public and private interest groups as well as firms), and research. Using this definition, a preliminary list of forums was compiled based on document and website research. The managers of the forums on this preliminary list were then contacted individually and asked to name additional forums they are aware of. The idea behind this snowballing approach was to take advantage of the crowd expertise of the individuals directly involved in forum work. The list was completed over several rounds of website research and snowballing. Only national-level forums were included (no local, regional, or cross-national forums). 
The coding of the different orientations of forum purpose is based on document analysis. In particular, the self-descriptions provided by the forums on their webpages and their legal statutes (many forums are either societies or foundations according to Swiss law) served as sources of information about forum purposes. From these documents, elements indicating aspects of forum purpose were extracted and collected in a protocol. This protocol served as a basis from which orientations were coded by hand. For sector orientation, a three-level scale was applied, differentiating between strong, medium, and weak sector orientation. Strong sector orientation was coded if most or all of the stated purposes of a forum refer to a single sector. Medium sector orientation was coded if about half of the stated forum purposes refer to a single sector, or if a sector-specific purpose is explicitly described as one of the central objectives (among few others). Weak sector orientation was coded if sector-specific purposes are highlighted somewhat disproportionally but still constitute a minority of all stated purposes or were explicitly indicated as side aspects. Finally, a forum is considered balanced if all three sector orientations are explicitly mentioned with none of them dominating, or if there is an official statement that the forum is meant to act as an arbitrator or broker between the sectors. In general, the coding of sector orientations was done rather "conservatively", meaning that, in case of doubt, a forum was considered balanced. For simplicity, maximum one sector orientation was assigned to a given forum, even though it could be argued that certain forums have two orientations, as in the hypothetical example of the government advisory board above.

Advocacy orientation is also coded on a strong-medium-weak scale. Strong is coded for forums where advocacy is explicitly highlighted as one of the main purposes of the forum (e.g. as the first- or second-mentioned purpose). Medium advocacy orientation means that advocacy appears among several other forum purpose but does not particularly stand out. Weak advocacy orientation means that advocacy does not appear at all or has a negligible 
stance compared to other aspects of purpose, and instead, forum purposes such as information exchange, networking, or the establishment of mutual understanding are emphasized.

Figure 2 shows the result of the forum classification. It illustrates the distribution of the sector and advocacy orientations in the set of 36 forums. As in Figure 1, the three sector orientations appear as scalars on a plane, with balanced forums in the center. The dashed concentric circles represent the three levels of sector orientation $(+=$ weak, $++=$ medium, $+++=$ strong). As only one orientation per forum was coded, all forums lie on one of the scalars. Advocacy orientation is represented by the three levels in the respective boxes $(+=$ weak, ++ $=$ medium,$+++=$ strong). The numbers in the Figure represent the individual forums whose names are reported in the notes below the Figure.

[Figure 2 here]

For further illustration and substantiation, Table 1 summarizes the purposes of selected forums with characteristics close to the eight ideal types that result from combining the extremes on the two dimensions of forum purpose. The table describes for each of the selected forums how sector and advocacy orientations are manifested in the documents analyzed, and provides additional information on organizational aspects, membership composition, activities and outputs of the forums.

[Table 1 here] 
Figure 2 shows that all three sector orientations as well as advocacy orientation are empirically relevant. Four results back this conclusion. First, with respect to sector orientation, not even half of the forums are balanced forums (15 out of 36), even though sector orientation was coded cautiously. Thus, notions in the literature according to which forums are "neutral" spaces serving the general public interest (Imperial 2005; Vasseur et al. 1997; Emerson et al. 2012) have to be treated with care, at least in the context of an integrative definition of forums.

Second, the non-balanced forums appear on all three scalars. This suggests a reconsideration of the predominant view in the existing forum literature according to which forums are either balanced or have a government orientation (Imperial 2005; Emerson et al. 2012; Vasseur et al. 1997). Several branches of literature thus far barely linked to forum research could improve the understanding of non-balanced forums, especially research-oriented and interest group-oriented forums. As for research-oriented forums, the literature on the science-policy interface (e.g., Keller 2009; Weber et al. 2017; Edelenbos et al. 2011; Cvitanovic et al. 2015; Cairney et al. 2016) has accumulated extensive knowledge on the factors that allow researchers to interact successfully with policy makers and interest groups. This literature could serve as a valuable resource for studying research-oriented forums, but also for analyzing the roles of researchers in other types of forums (e.g. their roles as advisors in government-oriented forums). As for the study of interest group-oriented forums, the literature on lobbying and interest groups (Berry and Wilcox 2015; Hojnacki et al. 2012) can potentially be useful. It provides in-depth knowledge on the strategies that interests groups apply when trying to influence governance. This knowledge can contribute to a better understanding of the motivations and behaviors of actors involved in interest group-oriented 
forums. Holyoke (2003) for example studied how interest groups choose between different institutional venues for lobbying.

Third, with respect to advocacy orientation, Figure 2 shows that about half of the forums have a medium or strong advocacy orientation (19 out of 36). This means that forums are very often not only venues for internal interactions, but also aim at advocating their shared interests and beliefs vis-à-vis decision-makers or the public.

Fourth, in line with our theoretical claims, the empirical application to 36 Swiss forums suggests that the two dimensions of forum purpose are independent, as there is variation with regard to advocacy orientation on each of the three sector scalars. While forums with government-orientations tend to have a weaker advocacy orientations compared to interest group-oriented forums, at least two out of the 10 government-oriented forums have a medium advocacy orientation.

There are several constraints regarding the representativeness of the 36 forums and, accordingly, the generalizability of the findings. The sample of our empirical application stems from a particular issue domain (habitat and land use governance) in a particular country (Switzerland) and is limited to forums active at the national level (thus excluding regional or local forums). It is not clear whether the same level of diversity in forum purposes exists in other contexts. For example, it could be hypothesized that forums with a government orientation are more frequent in countries where land use and habitat governance is more strongly controlled by the central government than in Switzerland. However, the opposite is also conceivable: given that the Swiss public administration has relatively limited resources as compared to international standards and hence depends on knowledge from outside the administration (Sciarini et al. 2015), government-oriented forums might be particularly frequent in Switzerland. 
Nonetheless, there is little reason to belief that the basic conclusions drawn from the 36 Swiss forums are idiosyncratic, and that the two dimensions should be meaningless in other contexts. After all, the challenges Switzerland faces in habitat and land use governance resemble those of other countries and regions with high population density and similar land use patterns. Of course, the exact reactions of the actors to these challenges depend on the system context, such as the nature of policy problems, the type of jurisdictions, as well as the complexity or the level of value conflict (Bryson et al. 2006; Emerson et al. 2012; Ansell and Gash 2008; Weber et al. 2017). Similarly, it is possible that different distributions of forum purposes would be found among regional and local forums (as compared to the national-level forums analyzed here), however, there is little reason to expect that there is no variation along the two dimensions of forum orientation.

The analysis of the 36 forums also raises methodological questions regarding the empirical assessment of forum purpose. The analysis in this paper relies on publicly available documents to measure sector and advocacy orientations. The disadvantage of this approach is that the coder might have incomplete or biased information about the "true" purpose of the forums under scrutiny. Ideally, the information gained from document analysis should be matched with data from surveys or interviews among forum managers and members.

\section{Forum Purpose and the Big Questions in Forum Research}

This section discusses how the two dimensions of forum purpose are relevant for at least three of the most frequently discussed questions in forum research. First, in the existing literature on forums, one outstanding question deals with the factors enabling forums to produce given outputs and related forum effectiveness (Quick and Feldman 2014; Sørensen and Torfing 2011; Van Meerkerk et al. 2015; Fischer and Schläpfer 2017; Bryson et al. 2006; Ansell and Gash 2008; Krick 2015; Emerson et al. 2012). Both dimensions of forum purpose 
introduce an important differentiation to this question. In fact, the sector or advocacy orientation of forums fundamentally influences the kinds of outputs that forums can be expected to produce. For example, it could be argued that government-oriented forums should be successful in producing policy blueprints or management plans, while this is not necessarily the case for research-oriented forums. Conversely, research-oriented forums should be capable of disseminating research knowledge and facilitating practice-informed research while this is not necessarily an expectation placed on government-oriented forums. Thus, the dimensions of forum purpose help focusing on the right outputs for the right types of forums and help to avoid "unfair" evaluations (Agranoff 2006).

A second frequently discussed set of questions in existing studies on forums deals with the importance of forums for the governance of society and politics in general (Klijn and Skelcher 2007; Ansell and Gash 2008). The two dimensions of forum purpose add to these questions by pointing to the fact that forums can take various functions in the wider governance system (Lubell 2013). They can act as simple coordination venues (balanced forums) but also serve the specific needs of specific societal sectors (forums with sector orientations). Forums with a strong advocacy orientation might take similar roles as advocacy coalitions, and might provide important venues for influencing policy processes. Another question related to the role of forums in governance systems is the one about the complementarity, redundancy, or interplay among several forums (Landau 1969; Fischer et al. 2017). For example, it could be hypothesized that redundancy results from two forums with similar orientations, whereas two forums with different orientations are likely to be complementary even if they deal with the same issue.

A third question that has attracted comparatively less attention from scholars thus far deals with the benefits that forums bring to individual actors (Fischer and Leifeld 2015; Provan and Milward 2001; Feiock and Scholz 2010; Thomson and Perry 2006), and the motivations of 
individual actors to participate in forums (Gustafson and Hertting 2017; Ansell and Gash 2008). In fact, it is likely that forums with different purposes attract different actor groups. Thus, awareness of forum purpose is an important step towards understanding why certain actors participate in a forums and other do not. For example, a strong advocacy orientation might attract actors that share the values of the forum but deter other actors who are not completely in line with the forums' ideals (Koontz and Johnson 2004; Fischer and Leifeld 2015; Gustafson and Hertting 2017). Furthermore, if the orientation of forums has an impact on motivations for participation, that might also influence the willingness of actors to contribute resources and - indirectly - the forum's capacity to produce certain outputs.

\section{Conclusion}

A central claim of this article is that different forums - broadly defined as organizations specialized in cross-sector coordination - have different, specific purposes beyond serving the general public interest. This element of self-interest tends to get little attention in the literature on forums. The article thus develops a meaningful way of characterizing forums according to their different purposes, based on arguments found in the various strands of relevant existing literature. It suggests a two-dimensional concept of forum purpose. The first dimension is sector orientation and assesses the degree to which a forum serves the needs of a specific societal sector. The second dimension, advocacy orientation, describes the extent to which a forum is oriented towards advocating the shared interests or values of its members.

An empirical analysis of the purposes of 36 forums active in Swiss habitat and land use policy shows that the proposed dimensions of forum purpose are empirically relevant. More than half of the forums have a clear sector orientation, and about half of the forums have a medium or strong advocacy orientation. The article then argues that taking into account this diversity is important when addressing the big questions of forum research. These questions 
deal with the capacity of forums to produce outputs, their roles in the overall governance system, as well as the benefits they provide to members. Answers to these questions are likely to vary depending on both dimensions of forum purpose.

While the two dimensions of forum purpose can be understood as continuous variables, they can also serve as a basis for a typology of forums. A typology with ideal types can be useful for sorting cases. It can help defining the spectrum of cases that should be considered, or it can support the selection of a sub-set of forums for an empirical study on a given research question. Furthermore, the ideal types can be used as building blocks in theory construction (Collier et al. 2012). For example, the types can be used for specifying the intervening factor in a contingent relationship between two variables ("typological theories" according to George and Bennett 2005). Such an application was discussed above where it was argued that the categorization of forums according to forum purpose can help explaining which types of forums are likely to produce which kinds of outputs, in configuration with given other factors.

\section{Acknowledgements}

This work was supported by the Swiss Federal Institute of Aquatic Science and Technology (Eawag). We thank the three anonymous reviewers for their helpful comments which allowed us to improve the article substantially.

\section{Endnotes}

${ }^{1}$ Note that the goal of this article is not a systematic literature review. However, it considers several existing theoretical frameworks which are based on systematic literature reviews (Bryson et al. 2006; Emerson et al. 2012; Fischer and Leifeld 2015; Thomson and Perry 2006; Sørensen and Torfing 2011; Ansell and Gash 2008; Hardy 2010). 
${ }^{2}$ There are several possible alternatives to the label "interest group sector". In the sciencepolicy interface literature "practice" has a similar meaning as interest group sector, however, the distinction between the government and the practice sector is vague. Another option would be "private sector", however, this term tends to exclude public interest groups according to established understandings of the term. Finally, the term "stakeholder sector" could be considered. However, stakeholders arguably comprise research. 


\section{References}

Agranoff, R.. 2006. Inside collaborative networks: Ten lessons for public managers. Public Administration Review 66 (s1):56-65.

Andrews, R., and T. Entwistle. 2010. Does Cross-Sectoral Partnership Deliver? An Empirical Exploration of Public Service Effectiveness, Efficiency, and Equity. Journal of Public Administration Research and Theory 20 (3):679-701.

Ansell, C., and A. Gash. 2008. Collaborative Governance in Theory and Practice. Journal of Public Administration Research and Theory 18 (4):543-71.

Bates, L. E., M. Green, Rosemary L., and I. Walker. 2013. The Influence of Forums and Multilevel Governance on the Climate Adaptation Practices of Australian Organizations. Ecology and Society 18 (4).

Bauer, A., and R. Steurer. 2014. Innovation in climate adaptation policy: are regional partnerships catalysts or talking shops? Environmental Politics 23 (5):818-838.

Berardo, R. 2009. Generalized Trust in Multi-organizational Policy Arenas: Studying Its Emergence from a Network Perspective. Political Research Quarterly 62 (1):178189.

Berardo, R., T. Olivier, and A. Lavers. 2015. Focusing Events and Changes in Ecologies of Policy Games: Evidence from the Paraná River Delta. Review of Policy Research 32 (4):443-464.

Berry, J. M., and C. Wilcox. 2015. Interest group society. London:Routledge.

Bidwell, R. D., and C. M. Ryan. 2006. Collaborative Partnership Design: The Implications of Organizational Affiliation for Watershed Partnerships. Society \& Natural Resources 19 (9):827-843. 
Bryson, J. M., B. C. Crosby, and M. Middleton Stone. 2006. The Design and Implementation of Cross-Sector Collaborations: Propositions from the Literature. Public Administration Review 20 (s1):45-55.

Cairney, P., K. Oliver, and A. Wellstead. 2016. To Bridge the Divide between Evidence and Policy: Reduce Ambiguity as Much as Uncertainty. Public Administration Review 76 (3):399-402.

Carr, A., and R. Wilkinson. 2005. Beyond Participation: Boundary Organizations as a New Space for Farmers and Scientists to Interact. Society \& Natural Resources 18 (3):255265.

Collier, D., J. Laporte, and J. Seawright. 2012. Putting Typologies to Work: Concept Formation, Measurement, and Analytic Rigor. Political Research Quarterly 65 (1):217-232.

Crona, B. I., and J. N. Parker. 2011. Network Determinants of Knowledge Utilization: Preliminary Lessons From a Boundary Organization. Science Communication 33 (4):448-471.

- 2012. Learning in Support of Governance: Theories, Methods, and a Framework to Assess How Bridging Organizations Contribute to Adaptive Resource Governance. Ecology and Society 17 (1).

Cvitanovic, C., A. J. Hobday, L. Van Kerkhoff, S. K. Wilson, K. Dobbs, and N. A. Marshall. 2015. Improving knowledge exchange among scientists and decision-makers to facilitate the adaptive governance of marine resources: A review of knowledge and research needs. Ocean \& Coastal Management 112:25-35.

Diaz-Kope, L., and K. Miller-Stevens. 2015. Rethinking a Typology of Watershed Partnerships: A Governance Perspective. Public Works Management \& Policy 20 (1):29-48. 
Dür, A., and D. De Bièvre. 2007. The Question of Interest Group Influence. Journal of Public Policy 27 (1):1-12.

Edelenbos, J., A. Van Buuren, and N. Van Schie. 2011. Co-producing knowledge: joint knowledge production between experts, bureaucrats and stakeholders in Dutch water management projects. Environmental Science \& Policy 14 (6):675-84.

Emerson, K., and T. Nabatchi. 2015. Collaborative Governance Regimes. Washington DC: Georgetown University Press.

Emerson, K., T. Nabatchi, and S. Balogh. 2012. An Integrative Framework for Collaborative Governance. Journal of Public Administration Research and Theory 22 (1):1-29.

Feiock, R. C., and J. Scholz. 2010. Self-Organizing Federalism. Cambridge/New York: Cambridge University Press.

Feldman, M. S., and A. M. Khademian. 2007. The Role of the Public Manager in Inclusion: Creating Communities of Participation. Governance 20 (2):305-324.

Fischer, M., M. Angst, and S. Maag. 2017. Co-Participation in Swiss Water Policy Forums. International Journal of Water Resources Development online.

Fischer, M., and P. Leifeld. 2015. Policy forums: Why do they exist and what are they used for? Policy Sciences 48 (3):363-382.

Fischer, M., and I. Schläpfer. 2017. Metagovernance and policy forum outputs in Swiss environmental politics. Environmental Politics 26 (5): 870-92.

George, A. L., and A. Bennett. 2005. Case Studies and Theory Development in the Social Sciences. Cambridge/London: MIT Press.

Giebels, D., A. Van Buuren, and J. Edelenbos. 2015. Using knowledge in a complex decision-making process-Evidence and principles from the Danish Houting project's ecosystem-based management approach. Environmental Science \& Policy 47:53-67. 
Glasbergen, P.. 2011. Understanding partnerships for sustainable development analytically: the ladder of partnership activity as a methodological tool. Environmental Policy and Governance 21 (1):1-13.

Gustafson, P., and N. Hertting. 2017. Understanding Participatory Governance: An Analysis of Participants' Motives for Participation. The American Review of Public Administration 37 (5):538-549.

Guston, D. H. 2001. Boundary Organizations in Environmental Policy and Science: An Introduction. Science, Technology, \& Human Values 26 (4):399-408.

Hahn, T., P. Olsson, C. Folke, and K. Johansson. 2006. Trust-building, Knowledge Generation and Organizational Innovations: The Role of a Bridging Organization for Adaptive Comanagement of a Wetland Landscape around Kristianstad, Sweden. Human Ecology 34 (4):573-592.

Hahn, T., and J. Pinkse. 2014. Private Environmental Governance Through Cross-Sector Partnerships: Tensions Between Competition and Effectiveness. Organization \& Environment 27 (2):140-160.

Hardy, S. D. 2010. Governments, group membership, and watershed partnerships. Society and Natural Resources 23 (7):587-603.

Hojnacki, M., D. C. Kimball, F. R. Baumgartner, J. M. Berry, and B. L. Leech. 2012. Studying Organizational Advocacy and Influence: Reexamining Interest Group Research. Annual Review of Political Science 15:1-21.

Holyoke, T. T. 2003. Choosing Battlegrounds: Interest Group Lobbying Across Multiple Venues. Political Research Quarterly 56 (3):325-336.

Huxham, C., S. Vangen, C. Huxham, and C. Eden. 2000. The challenge of collaborative governance. Public Management: an International Journal of Research and Theory 2 (3):337-358. 
Imperial, M. T. 2005. Using Collaboration as a Governance Strategy: Lessons From Six Watershed Management Programs. Administration \& Society 37 (3):281-320. Ingold, K., and F. Varone. 2012. Treating Policy Brokers Seriously: Evidence from the Climate Policy. Journal of Public Administration Research and Theory 22 (2):319346.

Jenkins-Smith, H. C., D. Nohrstedt, C. M. Weible, and P. A. Sabatier. 2014. The Advocacy Coalition Framework: Foundations, Evolution, and Ongoing Research. In Theories of the Policy Process, ed. C. M. Weible and P. A. Sabatier. Boulder, CO: Westview Press, 183-224.

Keller, A. C. 2009. Science in Environmental Policy: The Politics of Objective Advice. Cambridge, MA: MIT Press.

Kinzig, A., and D. Starrett. 2003. Coping With Uncertainty: A Call for a New Science-Policy Forum. AMBIO: A Journal of the Human Environment 32 (5):330-335.

Klijn, E.-H., and C. Skelcher. 2007. Democracy and governance networks: Compatible or not? Public Administration 85 (3):587-608.

Koontz, T. M., and E. M. Johnson. 2004. One size does not fit all: Matching breadth of stakeholder participation to watershed group accomplishments. Policy Sciences 37 (2):185-204.

Koontz, T M., T. A. Steelman, J. Carmin, K. S. Korfmacher, C. Moseley, and C. W. Thomas. 2004. Collaborative environmental management: What roles for government? Washington, DC: Resources for the Future Press.

Koontz, T. M., and C.W. Thomas. 2006. What Do We Know and Need to Know about the Environmental Outcomes of Collaborative Management? Public Administration Review 66 (s1):111-121. 
Kowalski, A. A., and L. D. Jenkins. 2015. The role of bridging organizations in environmental management: examining social networks in working groups. Ecology and Society 20 82).

Krick, E. 2015. Negotiated expertise in policy-making: How governments use hybrid advisory committees. Science and Public Policy 42 (4):487-500.

Landau, M. 1969. Redundancy, Rationality, and the Problem of Duplication and Overlap. Public Administration Review 29 (4):346-58.

Leach, W. D., N. W. Pelkey, and P. A. Sabatier. 2002. Stakeholder partnerships as collaborative policymaking: Evaluation criteria applied to watershed management in California and Washington. Journal of Policy Analysis and Management 21 (4):645670.

Leach, W. D., C. M. Weible, S. R. Vince, S. N. Siddiki, and J. C. Calanni. 2014. Fostering Learning through Collaboration: Knowledge Acquisition and Belief Change in Marine Aquaculture Partnerships. Journal of Public Administration Research and Theory 24 (3):591-622.

Lubell, M. 2004. Collaborative Environmental Institutions: All Talk and No Action? Journal of Policy Analysis and Management 23 (3):549-573.

_ 2013. Governing Institutional Complexity: The Ecology of Games Framework. Policy Studies Journal 41 (3):537-559.

Lubell, M., A. D. Henry, and M. McCoy. 2010. Collaborative Institutions in an Ecology of Games. American Journal of Political Science 54 (2):287-300.

Lubell, M., M. Schneider, J. T. Scholz, and M. Mete. 2002. Watershed Partnerships and the Emergence of Collective Action Institutions. American Journal of Political Science 46 (1):148-163. 
Mandell, M., and T. Steelman. 2003. Understanding what can be accomplished through interorganizational innovations The importance of typologies, context and management strategies. Public Management Review 5 (2):197-224.

Margerum, R. 2008. A Typology of Collaboration Efforts in Environmental Management. Environmental Management 41 (4):487-500.

Moore, E. A., and T. M. Koontz. 2003. Research Note A Typology of Collaborative Watershed Groups: Citizen-Based, Agency-Based, and Mixed Partnerships. Society \& Natural Resources 16 (5):451-460.

Provan, K. G., and H. B. Milward. 2001. Do Networks Really Work? Public Administration Review 61 (4):414-423.

Quick, K. S., and M. S. Feldman. 2014. Boundaries as Junctures: Collaborative Boundary Work for Building Efficient Resilience. Journal of Public Administration Research and Theory 24 (3):673-695.

Sabatier, P. 1988. An Advocacy Coalition Framework of Policy Change and the Role of Policy-Oriented Learning Therein. Policy Sciences 21 (2/3):129-168.

Sciarini, P., M. Fischer, and D. Traber. 2015. Political Decision-Making in Switzerland. The Consensus Model under Pressure. Basingstoke/New York: Palgrave Macmillan.

Selsky, J. W., and B. Parker. 2005. Cross-Sector Partnerships to Address Social Issues: Challenges to Theory and Practice. Journal of Management 31 (6):849-73.

— 2010. Platforms for Cross-Sector Social Partnerships: Prospective Sensemaking Devices for Social Benefit. Journal of Business Ethics 94 (1):21-37.

Siddiki, S., and S. Goel. 2017. Assessing Collaborative Policymaking Outcomes: An Analysis of U.S. Marine Aquaculture Partnerships. The American Review of Public Administration 47 (2): 253-271 
Sørensen, E., and J. Torfing. 2011. Enhancing Collaborative Innovation in the Public Sector. Administration \& Society 43 (8):842-868.

Thomson, A. M., and J. L. Perry. 2006. Collaboration Processes: Inside the Black Box. Public Administration Review 66 (s1):20-32.

Van Meerkerk, I., J. Edelenbos, and E.-H. Klijn. 2015. Connective management and governance network performance: the mediating role of throughput legitimacy. Findings from survey research on complex water projects in the Netherlands. Environment and Planning C: Government and Policy 33 (4):746-764.

Vasseur, L., L. Lafrance, C.Ansseau, D.e Renaud, D. Morin, and T.Audet. 1997. Advisory Committee: A Powerful Tool for Helping Decision Makers in Environmental Issues. Environmental Management 21 (3):359-365.

Weber, E. P., D. Lach, and B. S. Steel, eds. 2017. New Strategies for Wicked Problems: Science and Solutions in the 21st Century. Corvallis: Oregon State University Press. 
Tables and Figures for USNR-2017-0277.R2 ("Why Government, Interest Groups, and Research Coordinate: The Different Purposes of Forums")

Figure 1

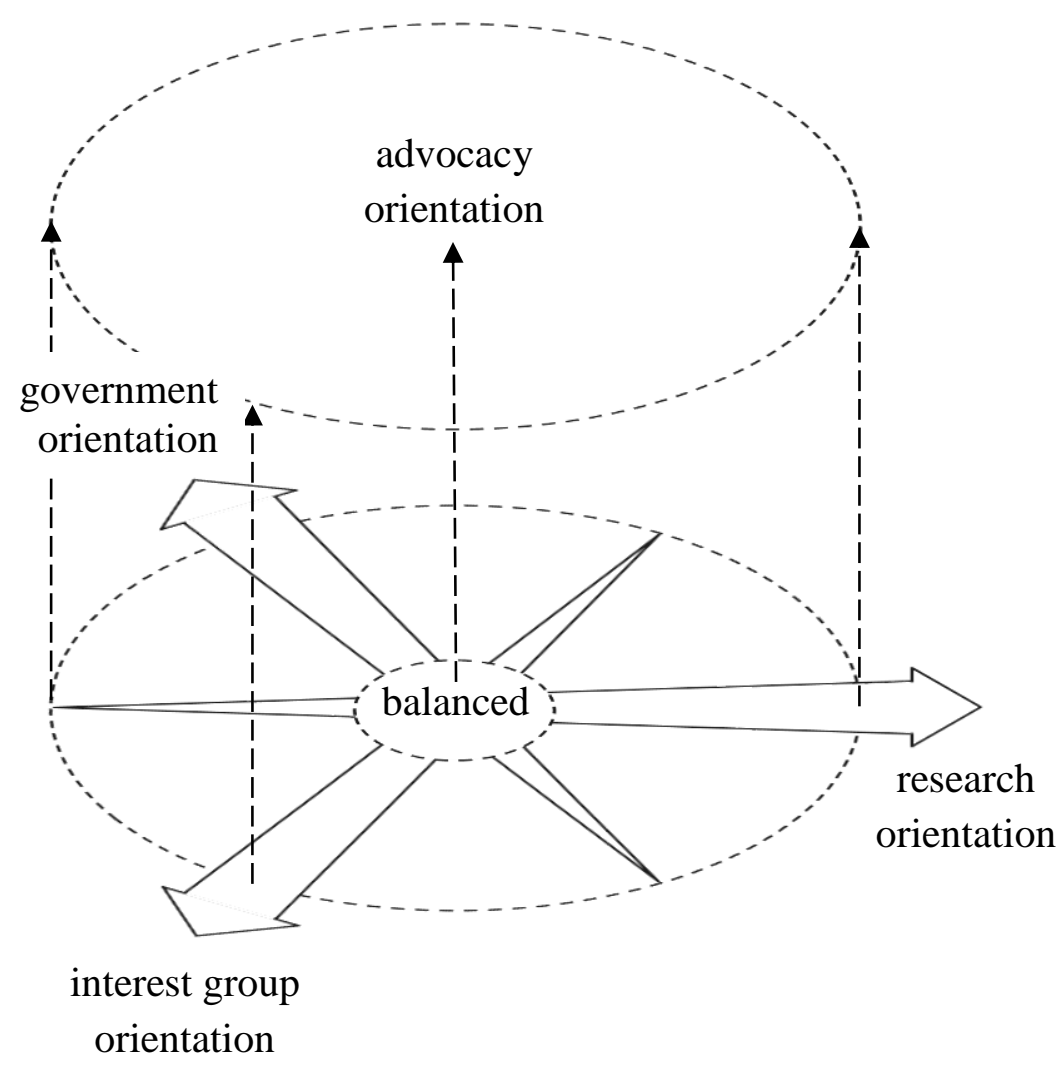


Figure 2

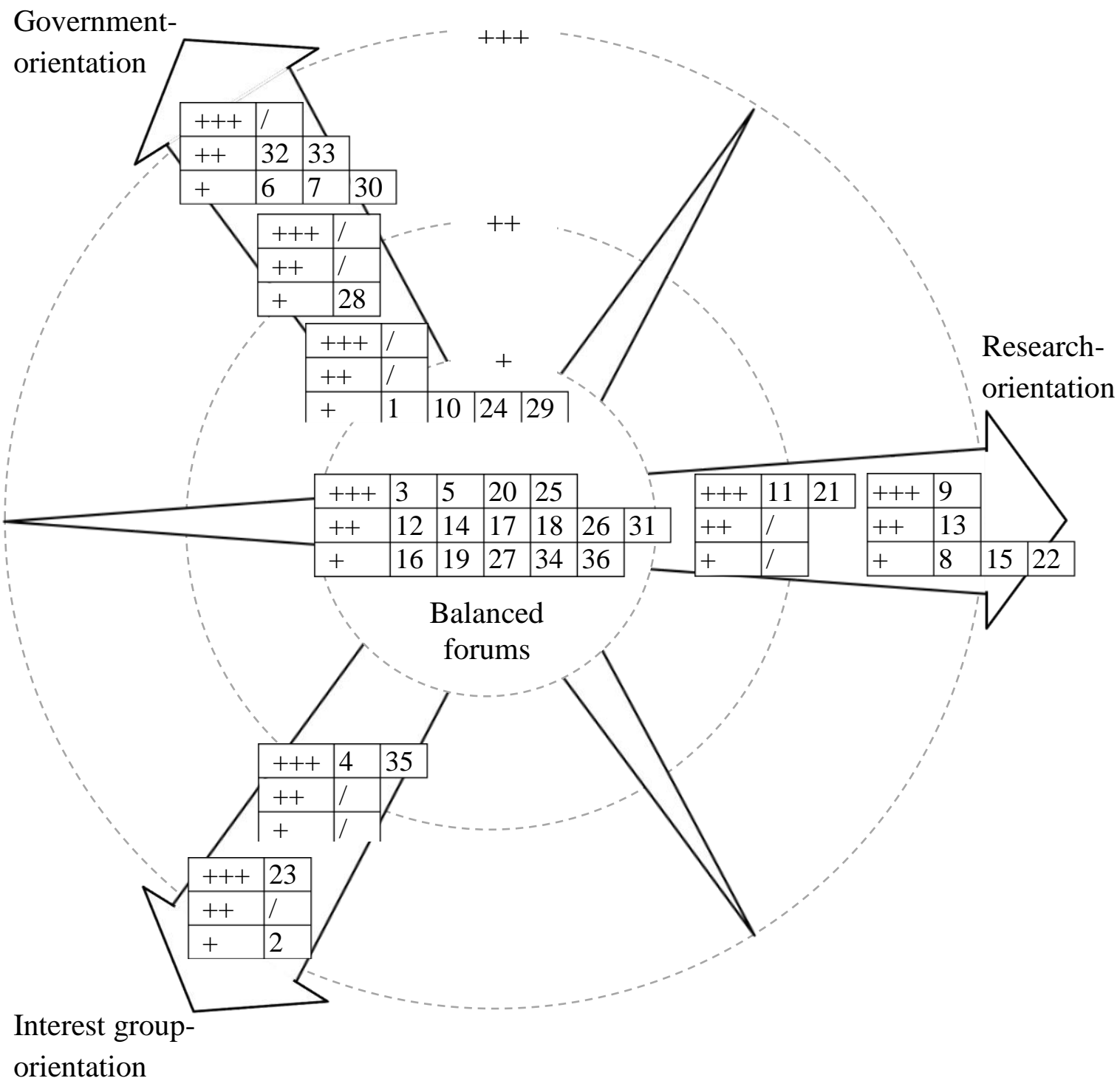

Notes: 1 Arbeitsgruppe für den Wald (AfW); 2 Agridea; 3 Bund Schweizer Landschaftsarchitekten und Landschaftsarchitektinnen (BSLA); 4 Verein für Ingenieurbiologie - Arbeitsgruppe (AG) Hochlagenbegrünung; 5 Verein für Ingenieurbiologie - AG Seeufer; 6 Eidgenössische Fachkommission für biologische Sicherheit (EFBS); 7 Eidgenössische Nationalpark Kommission (ENPK); 8 Forschungskommission Schweizerischer Nationalpark (FOK-SNP); 9 Forum Biodiversität; 10 Forum Früherkennung; 11 Forum Landschaft; 12 Fachverein Wald (FVW); 13 Interakademische Kommission Alpenforschung (ICAS); 14 Info Flora; 15 Parkforschung Schweiz; 16 Schweizerischer Forstverein (SFV); 17 SFV - AG Wald und Wildtiere; 18 SFV - AG Waldbiodiversität; 19 SFV - AG Waldplanung und -management; 20 Schweizerische Gesellschaft für Wildtierbiologie (SGW); 21 Schweizerische Kommission für die Erhaltung von Kulturpflanzen (SKEK); 22 Schweizerische Kommission für Polar- und Höhenforschung (SKPH); 23 Stiftung Landschaftsschutz; 24 Schweizerische Vereinigung für Landesplanung (VLP-ASPAN); 25 Verband Schweizer Abwasser- und Gewässerschutzfachleute (VSA); 26 VSA - Centre de Compétences Gewässer; 27 Wasser Agenda 21 - AG Einzugsgebietsmanagement; 28 Wasser Agenda 21 - AG 
Renaturierung; 29 Arbeitsgruppe Geologie und Naturgefahren (AGN); 30 Eidgenössische Expertenkommission Lawinen und Steinschlag (EKLS); 31 Fachleute Naturgefahren (FAN); 32 Lenkungsausschuss Intervention Naturgefahren (LAINAT); 33 Plattform Naturgefahren (PLANAT); 34 Schweizerische Interessengemeinschaft Lawinenwarnsysteme (SILS); 35 Schweizerischer Wasserwirtschaftsverband (SWV); 36 SWV - Kommission Hochwasserschutz, Wasserbau und Gewässerpflege (KOHS). 


\section{Table 1}

\begin{tabular}{|c|c|c|c|}
\hline 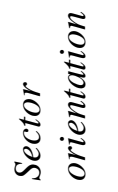 & 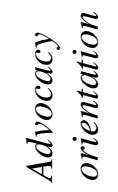 & $\begin{array}{l}\sim \\
\dot{0} 0 \\
. \Sigma \\
* \\
*\end{array}$ & \\
\hline$G+++$ & +++ & - & $\begin{array}{l}\text { Not represented among the } 36 \text { national-level forums active in Swiss habitat } \\
\text { and land use governance. }\end{array}$ \\
\hline \multirow[t]{2}{*}{$G+++$} & + & 6 & Swiss Expert Committee for Biosafety (EFBS) \\
\hline & & & $\begin{array}{l}\text { The EFBS is an expert committee appointed by the Swiss federal } \\
\text { government. It consists of } 15 \text { experts from all sectors with knowledge in } \\
\text { biosafety (mainly genetically modified, pathogenic, or alien organisms). It } \\
\text { meets about six times per year. } \\
\text { Sector orientation: The main purpose of the committee is to advise the } \\
\text { federal government on issues related to biosafety. A secondary purpose is to } \\
\text { give stakeholders a platform to present their priorities. Thus, two sector } \\
\text { orientations are present, but the first one is stronger. } \\
\text { Advocacy orientation: The official documents list } 10 \text { "duties" of the forum, } \\
\text { referring to consulting as well as publishing of recommendations and } \\
\text { assessments. The only reference to advocacy is a partial sentence saying that } \\
\text { the forum "informs [...] the public about its activities". This is not } \\
\text { considered sensitization. }\end{array}$ \\
\hline \multirow[t]{2}{*}{$R+++$} & +++ & 9 & Swiss Biodiversity Forum \\
\hline & & & $\begin{array}{l}\text { The Swiss Biodiversity Forum consists of eight experts (mainly from the } \\
\text { research sector) in the main steering committee, and a large number of } \\
\text { persons in the consulting plenary assembly (with various sectoral } \\
\text { backgrounds). Five persons are employed at the central office of the Forum. } \\
\text { Sector orientation: It describes itself as the scientific competence center on } \\
\text { issues of biodiversity. Apart from supporting research on biodiversity, it } \\
\text { aims at giving scientists a platform for co-operation with actors from policy } \\
\text { and practice. } \\
\text { Advocacy orientation: The forum declares in its mission statement that its } \\
\text { main purpose is to contribute to the achievement of the "Aichi Biodiversity } \\
\text { Targets", an international convention on biodiversity promotion. It wants to } \\
\text { act as an "initiator and accelerator to make biodiversity a key issue in all } \\
\text { policy fields and society". The main activities are knowledge production, } \\
\text { provision of implementation aid, communication, and promotion of its own } \\
\text { external visibility. }\end{array}$ \\
\hline \multirow[t]{2}{*}{$R+++$} & + & 22 & Swiss Committee on Polar and High Altitude Research (SKPH) \\
\hline & & & $\begin{array}{l}\text { The Committee is part of the Swiss National Academy of Science. It consists } \\
\text { of } 13 \text { members, mainly from research, but also from public administration. } \\
\text { Sector orientation: Its main purposes include representing Switzerland in } \\
\text { international committees on polar and high altitude research, and promoting } \\
\text { the careers of young scientists in the field. It is further active in early } \\
\text { recognition of research needs and issues as well as in transdisciplinary } \\
\text { science-policy dialogue. } \\
\text { Advocacy orientation: The forum publishes for science and practice, } \\
\text { organizes various events, bestows awards, and delegates representatives to } \\
\text { various scientific committees. It further declares that it wants to "sensitize } \\
\text { the public for high altitude research". However, this is just one sentence at } \\
\text { the end of a longer paragraph on its objectives and is weakly reflected in its } \\
\text { activities. }\end{array}$ \\
\hline$I+++$ & +++ & 23 & Swiss Foundation for Landscape Conversation \\
\hline
\end{tabular}




\begin{tabular}{|c|c|c|c|}
\hline & & & $\begin{array}{l}\text { Constituted as a foundation, its committee consists of } 15 \text { members from all } \\
\text { sectors. It has eight employees. } \\
\text { Sector orientation: The official documents mention six aims, all of which } \\
\text { refer to the overarching aim of protecting landscapes. Thus, it mainly serves } \\
\text { its members as a vehicle for joint representation of shared values. } \\
\text { Advocacy orientation: When describing its approach, the foundation } \\
\text { mentions consulting, education, as well as publishing of position papers and } \\
\text { assessments. All these activities aim at sensitizing and influencing decision- } \\
\text { makers and/or the public. }\end{array}$ \\
\hline \multirow[t]{2}{*}{$I+++$} & + & 2 & Agridea-Developing Agriculture and Rural Areas \\
\hline & & & $\begin{array}{l}\text { Agridea is a registered association and defines itself as a center of } \\
\text { competence for a productive, sustainable agriculture. Its board includes } \\
\text { actors from all sectors, with a bias towards private organizations in the fields } \\
\text { of agriculture and rural development (both non-profit and corporate). } \\
\text { Furthermore, it has about } 150 \text { employees, providing a broad spectrum of } \\
\text { services to farmers and public agencies. } \\
\text { Sector orientation: Its main purpose is to provide knowledge (on business- } \\
\text { related and technical issues) to farmers and other practitioners. It receives } \\
\text { financial support from several government offices, but its services primarily } \\
\text { target farmers. Thus, even though a government orientation can be discerned, } \\
\text { interest group orientation is the more pronounced sector orientation. } \\
\text { Advocacy orientation: All purposes mentioned in the official documents } \\
\text { refer to provision of knowledge through courses, guidelines, software, } \\
\text { consultation services, etc. There is no mentioning of any advocacy activities. }\end{array}$ \\
\hline \multirow[t]{2}{*}{$B$} & +++ & 5 & Working Group on Lakeshores of the Swiss Association of Bioengineers \\
\hline & & & $\begin{array}{l}\text { The Working Group is a sub-unit of the Swiss Association of Bioengineers, a } \\
\text { professional society organized as a registered association. In consists of } 11 \\
\text { members from all sectors. } \\
\text { Sector orientation: The forum provides on its homepage a list of "target } \\
\text { groups" which includes all sectors with no prioritization. } \\
\text { Advocacy orientation: The forum provides a list of aims, mostly referring to } \\
\text { conserving and improving the ecological quality of lakeshores. Almost all } \\
\text { aims involve sensitizing and influencing key stakeholders such as local } \\
\text { governments, agriculture, camping ground owners, and shipping companies. } \\
\text { It intends to achieve its goals by means of guidelines and other publications, } \\
\text { consulting, events, and awards. }\end{array}$ \\
\hline \multirow[t]{2}{*}{$B$} & + & 27 & Working Group on Catchment Management of Water Agenda 21 \\
\hline & & & $\begin{array}{l}\text { The Working Group is part of the Water Agenda 21, a registered association } \\
\text { that is financially supported by actors from all sectors. It consists of about a } \\
\text { dozen experts, representing all sectors. } \\
\text { Sector orientation: The aim of the working group is cooperation across } \\
\text { sectors in the management of water resources. It emphasizes that it serves all } \\
\text { actors involved in the "water economy" (which includes corporate actors, } \\
\text { non-profit organizations as well as actors of the public sector and from } \\
\text { science). None of these actor groups are particularly emphasized. } \\
\text { Advocacy orientation: The working group publishes fact sheets and other } \\
\text { materials for the actors involved in the water economy. The contents of these } \\
\text { materials are mostly technical and not targeted at the general public. There is } \\
\text { no indication that the Working Group engages in public debates. Instead, it } \\
\text { tries to arbitrate between conflicting priorities of the actors. }\end{array}$ \\
\hline
\end{tabular}


The Different Purposes of Forums 